\title{
New ice age, or just cold feet?
}

\section{Tempers boil over at a heated meeting on global cooling.}

\section{Norman Spinrad}

0 rbital Hilton, 14 March 2322. The highly touted First World Conference of Planetary Climatologists and Climatech Engineers on Global Cooling broke up in angry chaos on its opening day and fisticuffs were only averted by the quick action of hotel security staff, who pumped pax gas into the conference chamber before blows could be struck. It had been hoped that the neutral orbital venue would calm tempers, but unfortunately this did not prove to be the case.

The conference opened with a speech by Dr Vladimir Bunin, chairperson of the Committee of Concerned Climatologists, rehashing the charge that the past three centuries of effort by climatech engineers to counter the twentieth and twenty-first centuries' admittedly disastrous greenhouse warming had proven all too successful, and their meddling, if not speedily countered, was about to bring on a new ice age.

Bunin contended that the recent unplanned expansion of both polar ice caps, the increase in glaciation in the northern hemisphere, the return of winter snowfall as far south as Labrador and Moscow, and the icebergs sighted in the Bering Sea and off Tierra del Fuego were not - as the climatech engineers contend - isolated anomalies, easily corrected by adjustments to orbital mirrors and occluders and a diminished output by cloud-cover generators. Instead, he said, they were aspects of a dangerous global pattern leading to a new ice age that would devastate the agricultural breadbaskets of Siberia, Alaska, Canada and Lapland, upon which the Earth's 20 billion inhabitants depend.

He demanded the halving of the area of desert covered with mylar mirroring to lower the Earth's albedo and a redeployment of the orbital mirrors now sustaining the Gulf Stream to add more heat to the atmosphere. But the most heat was generated by his attack on Qwik-grow trees and the forestry programme.

"Far too many Qwik-grow trees have been planted, and now they are spreading like weeds, completely out of control," he declared. "It was one thing to reforest the Amazon basin, the American plains, the Indonesian archipelago and Europe while we were still burning fossil fuels, but now that our energy sources are all solar and thermonuclear, these vast and ever-expanding woodlands have created a severe atmospheric carbon dioxide deficit that has seriously diminished the greenhouse effect. This can only be remedied by a return to the mass burning of coal or the setting of immense forest fires - preferably both.'

This resulted not only in cries of outrage from the climatech engineer contingent, but the throwing of plastic coffee bulbs, styli, fruit, and other debris in his direction. Injury was prevented by the zero- $g$ conditions, which rendered this fusillade ineffective, but the frustration only added to the ire of the climatech engineers, and it was a good $20 \mathrm{~min}$ utes before enough order could be restored for Hans Goodkin of Climatech Solutions to deliver a scathing rebuttal.

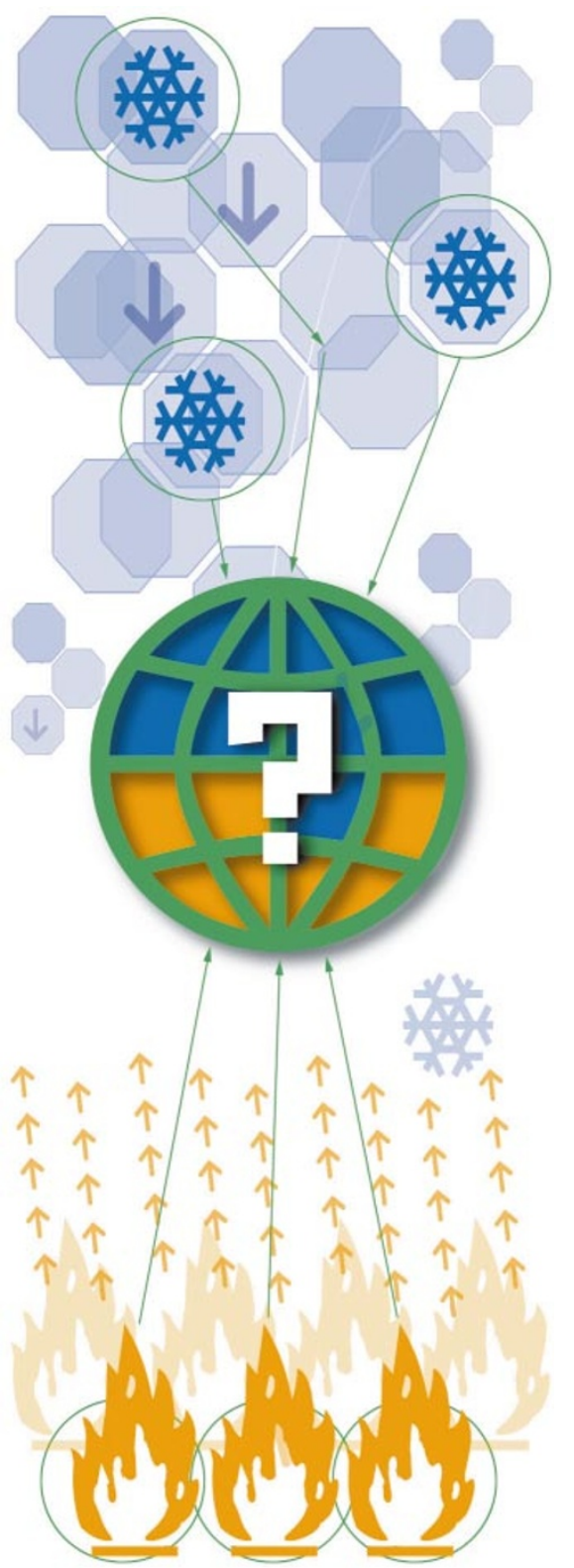

๑) 2000 Macmillan Magazines Ltd
"Burn coal! Why not bring back the internal combustion engine, and to hell with the ozone layer! Or better yet, the steam locomotive, and never mind the acid rain! Burn the forests? Why settle for half-measures? Let's just nuke the trees! And while we're at it, why not drop thermonuclear charges into the craters of active volcanoes? The resulting mass eruptions would pump plenty of carbon dioxide back into the atmosphere and the red-hot lava flows would really heat things back up! Let's bring back Vesuvius and Mount St Helens and Krakatoa!”

When the booing and hissing subsided, he continued in an even more sarcastic vein: "Dissolving the coral reefs we've rebuilt would release plenty of carbon dioxide too! And we could melt the ice-caps from orbit! And replace the mylar mirroring with black ash! After all, if we listen to you people, we'll have plenty of soot to spare!" Unwilling to wait for the uproar to die down, Goodkin just turned up the gain on his microphone to override it.

"Let Central Australia and the Sahara savannah once more become howling deserts - no problem, their millions of inhabitants can join the rest of the planet's new boat-people when the sea levels rise again and the world's reclaimed coastlands and islands return from whence they came!"

Improvised missiles began to fly again this time from the climatologists - or rather drift ineffectually in the general direction of Goodkin in the weightless conference chamber. "You're turning the Earth into a deep freeze to line your own pockets!" someone shouted.

"You climatological Luddite snake-oil salesmen want us to turn it back into a greenhouse oven so you can make your fortunes selling air-conditioners in Antarctica and iceboxes to Eskimos!" Goodkin shouted back.

At which point, the Concerned Climatologists attempted to storm the podium, swimming clumsily towards it through the air like a school of slow-motion sharks, and hotel security released the pax gas.

"What do a climatech engineer, a climatologist, a planet and a nymphomaniac have in common?" a reporter asked, several drinks later, in the bar.

"I'm afraid you're about to tell us," groaned another.

"They're much easier to heat up than cool down."

Norman Spinrad is a novelist, screenwriter, essayist, songwriter and sometime performer. His latest novel, Greenhouse Summer, is published by Tor Books. 